\title{
A Tale of Three Hydrophobicities: Impact of Constitutional Isomerism on Nanostructure Evolution and Electronic Communication in $\pi$-conjugated Peptides
}

\author{
Jessie P. Dibble ${ }^{\dagger}$, Clara Troyano-Valls ${ }^{\ddagger}$, John D. Tovar*,† \\ †Department of Chemistry and Department of Materials Science and Engineering, Johns \\ Hopkins University, 3400 North Charles Street, Baltimore Maryland 21218, United States
}

Table of Contents:

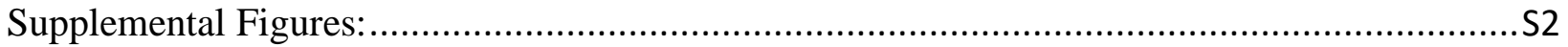

Synthesis Details and Molecular Characterization Data: ..............................................S7

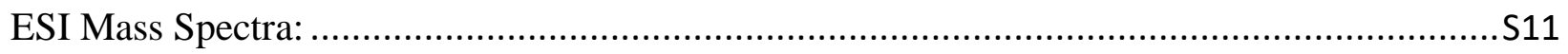

HPLC Traces of Purified Peptides ...................................................................... 18

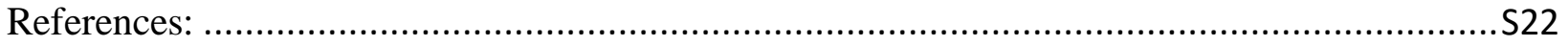




\section{Supplemental Figures:}
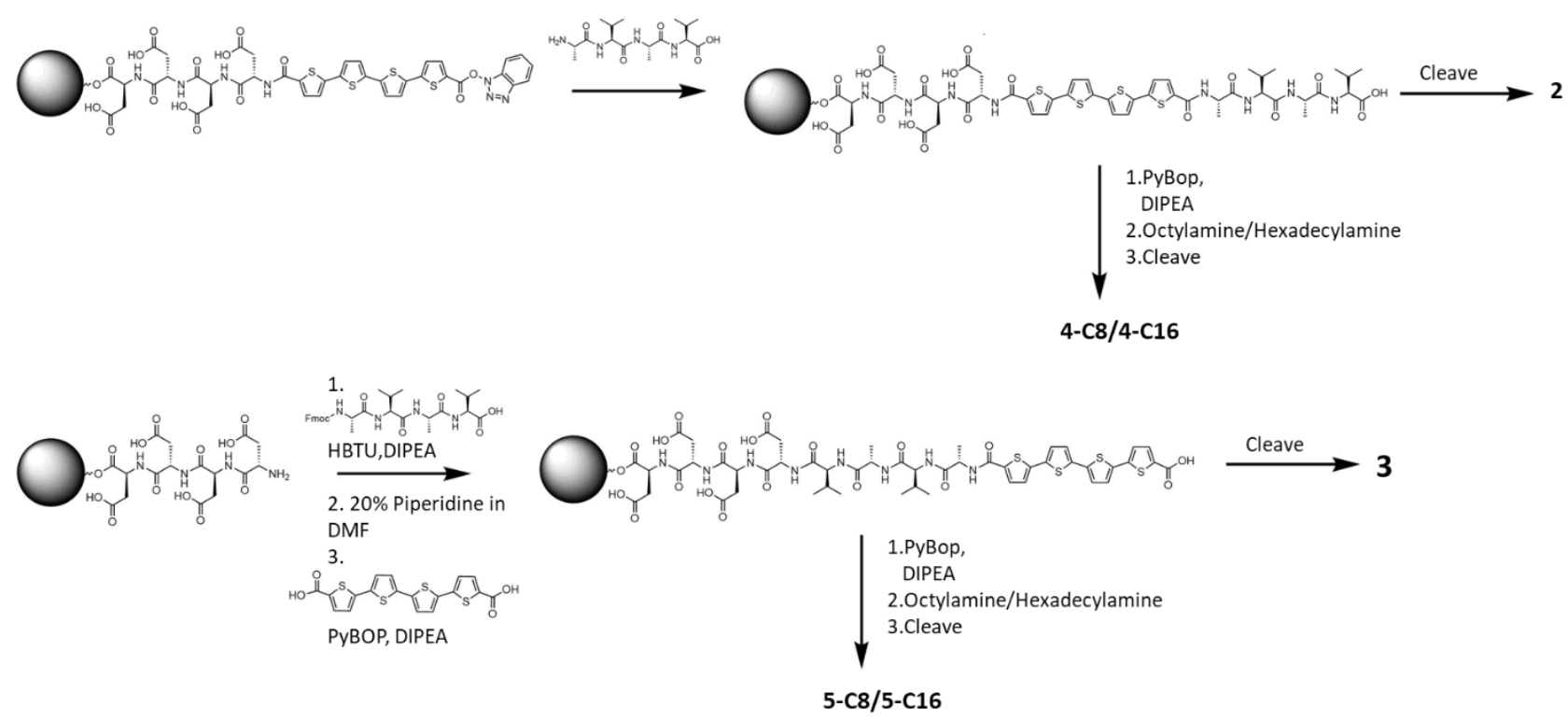

Figure S1. Peptide library was synthesized by standard solid-phase peptide synthesis adapted with an on-resin carboxylic acid activation procedure.
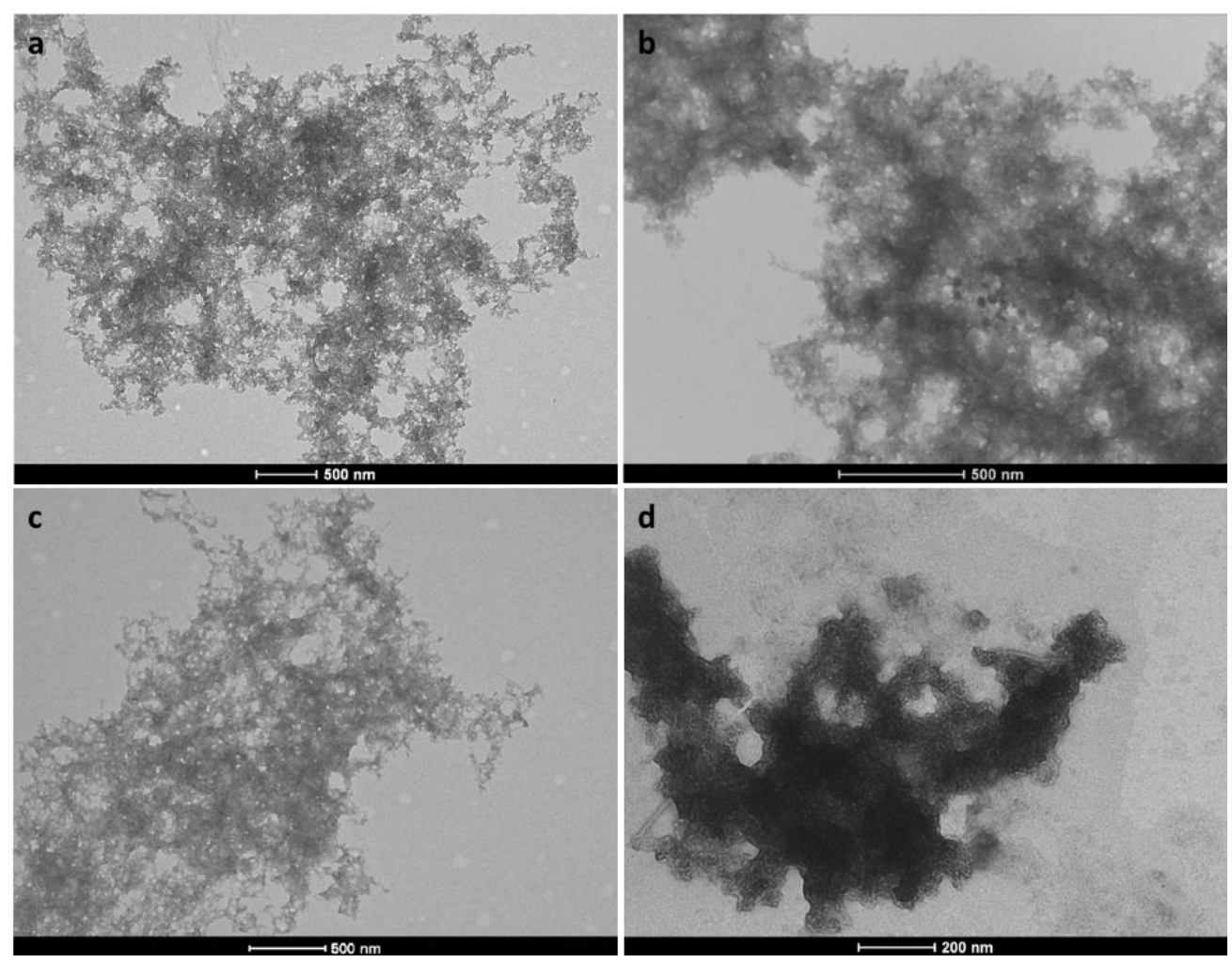

Figure S2. Transmission electron micrographs of basic-to-acidic processing of peptides (a) 4-C8 (b) 5-C8 (c) 4-C16 (d) 5-C16. 

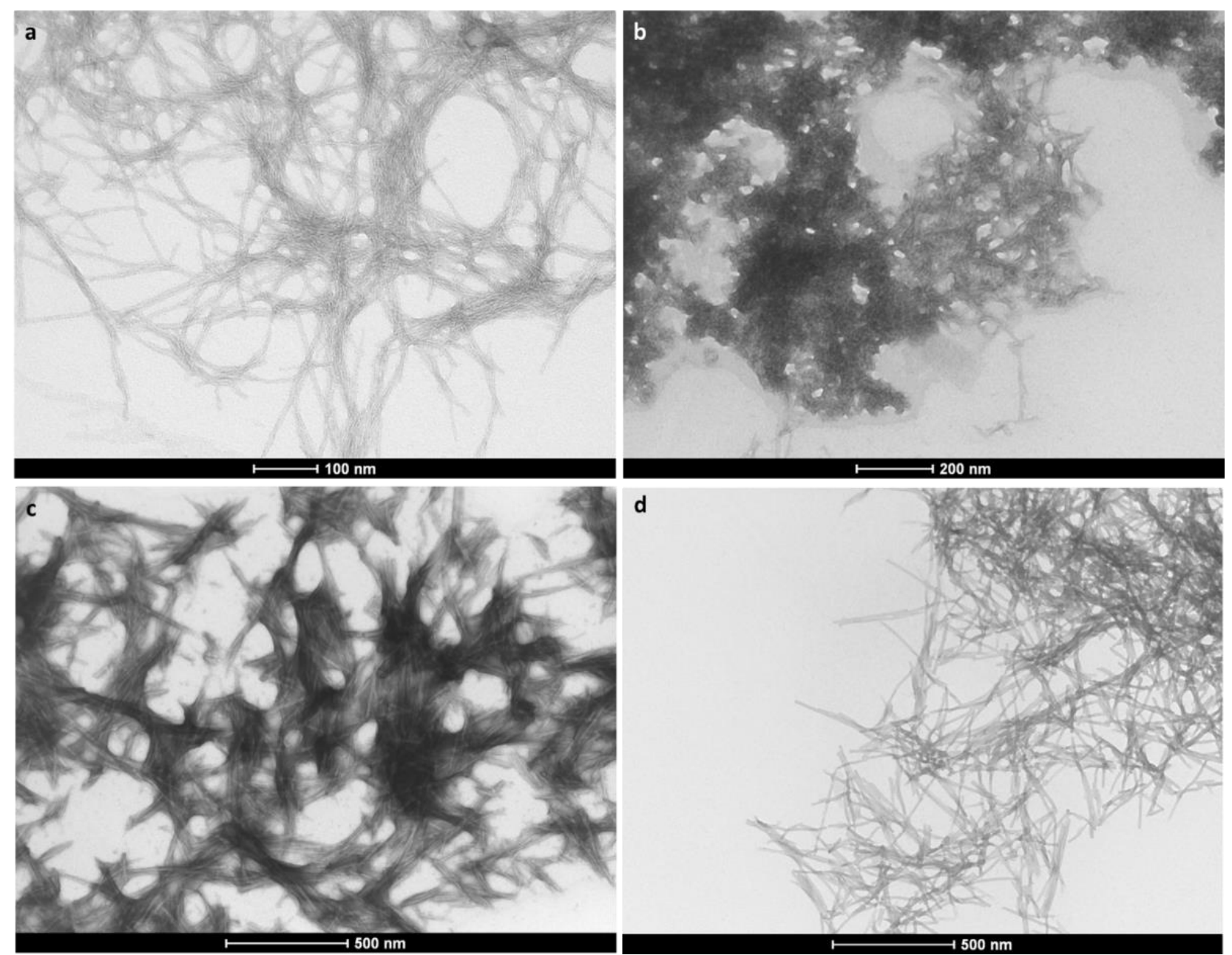

d

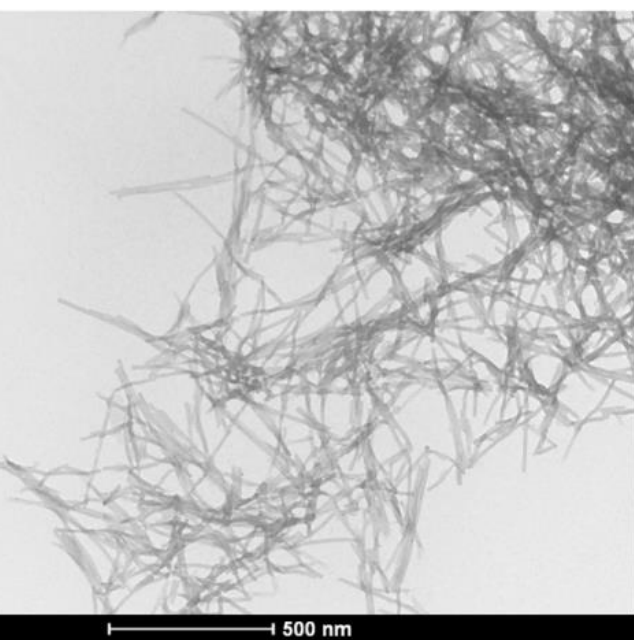

Figure S3. Transmission electron micrograph of (a) 1 and (b) 3 in basic-to-acidic assemblies and (c) 2 and (d) 3 in neutral-to-acidic assemblies. 

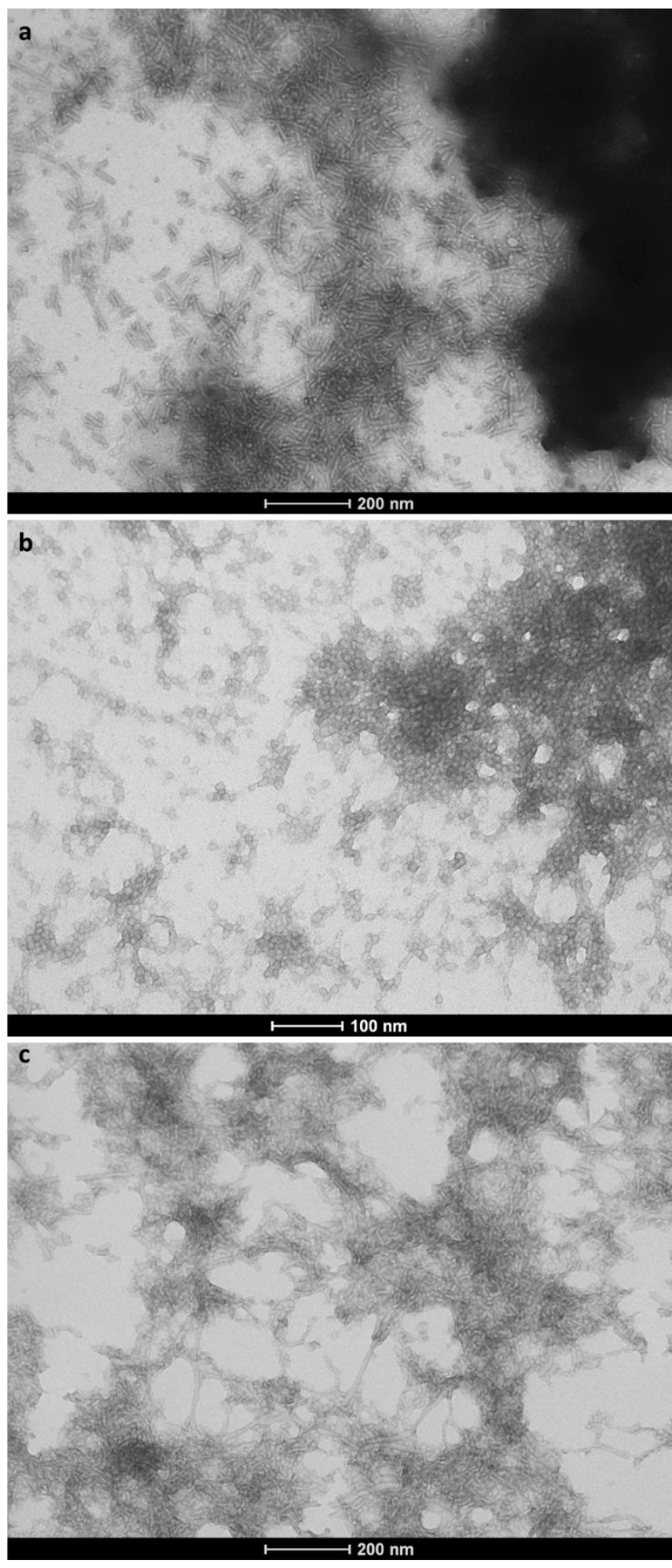

Figure S4. Representative transmission electron micrograph of (a) 4-C16 dissolved in buffer pH 7 after sonication, thermal annealing, and equilibration at room temperature for two weeks and 5C16 dissolved in (b) pH 7.0 and (c) 8.6 buffers, sonicated, thermally annealed for 24 hours and equilibrated at room temperature for two weeks. 

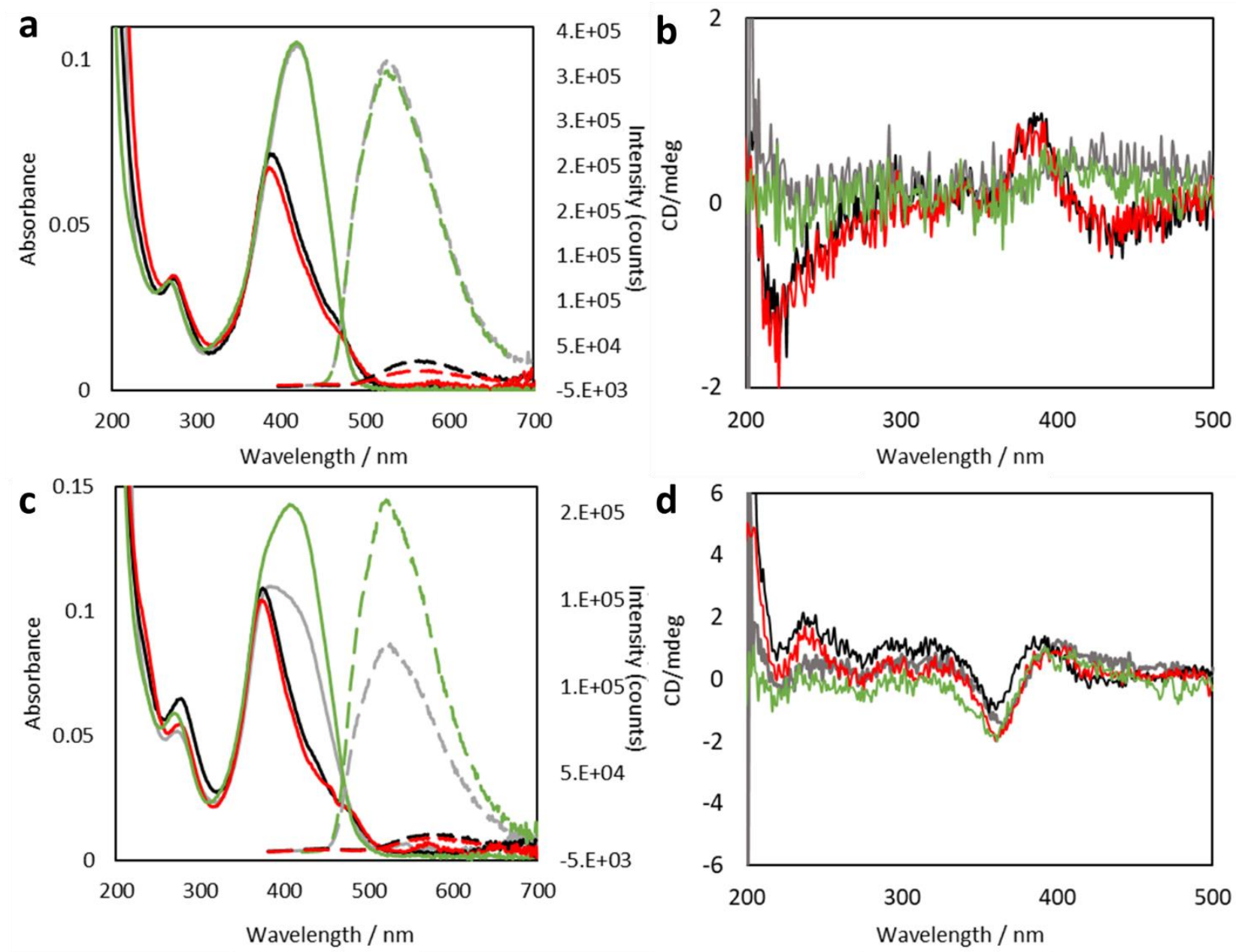

Figure S5. UV-Vis (left panels, solid) and photoluminescence (left panels, dashed), and CD (right panels) spectra for (a,b) 4-C8 (c,d) 5-C8 (e,f) in basic (grey), acidic (black), 30 minutes after acidification (red) and in thermally annealed samples $\mathrm{pH} 7$ (green). 

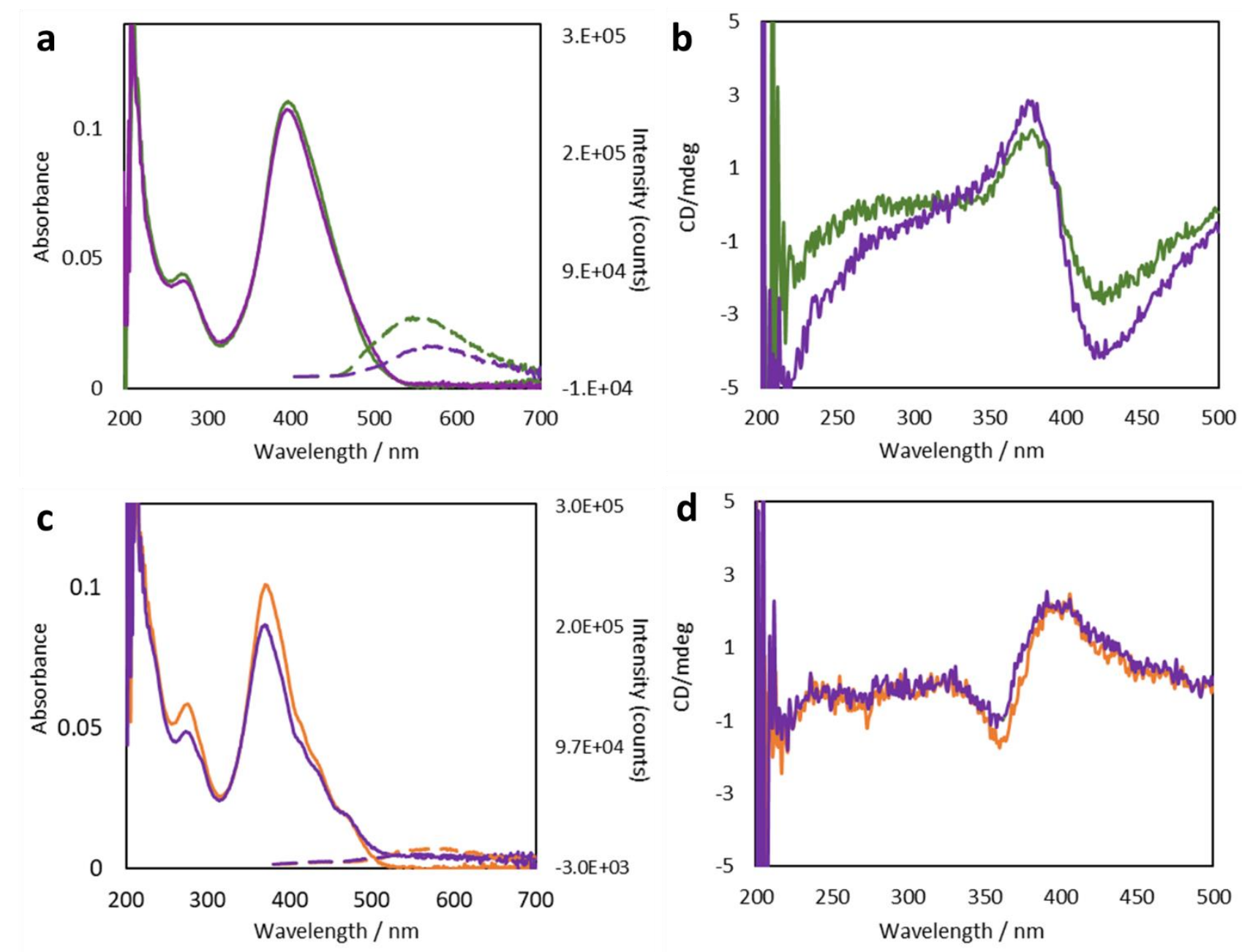

Figure S6. UV-Vis (left panels, solid lines), photoluminescence (left panels, dashed lines), and $\mathrm{CD}$ (right panels) spectra for 4-C16 (a,b) and 5-C16 in pH 8.6 buffer 16 hours (green traces), 24 hours (orange traces) and two weeks (purple traces) after thermal annealing. 
<smiles>CC(C)C(NC(=O)[C@H](C)NC(=O)c1ccc(-c2ccc(-c3ccc(-c4ccc(C(=O)N[C@@H](C)C(=O)N[C@@H](CC(=O)O)C(=O)N[C@@H](CC(=O)O)C(=O)N[C@@H](CC(=O)O)C(=O)O)s4)s3)s2)s1)C(=O)N[C@@H](CC(=O)O)C(=O)O</smiles>

HO-DDVA-OT4-AVDD-OH (1): Solid supported Wang-DDVA-NH 2 peptide $(0.2 \mathrm{mmol})$ was $N$ acylated with 5-bromothiophene-2-carboxylic acid and subjected to the standard Stille coupling procedure in the presence of 5,5'-bis- tributylstannyl-[2,2']-bithiophene $(0.1 \mathrm{mmol}, 0.07 \mathrm{~g})$ and $\mathrm{Pd}\left(\mathrm{PPh}_{3}\right)_{4}(0.008 \mathrm{mmol}, 0.009 \mathrm{~g})$. Following general cleavage, work-up, and HPLC purification, the peptide was obtained as a light orange powder $(0.017 \mathrm{mmol}, 9 \%)$. DATA UV-Vis $(\mathrm{H} 2 \mathrm{O}) \lambda / \mathrm{nm}$ (pH 10): 420. MS (ESI) m/z 1217.0 (M-1H) (calc. 1217.3), m/z 608.3 (M-2H)/2 (calc. 608.7).<smiles>CC(C)C(NC(=O)[C@H](C)NC(=O)[C@H](NC(=O)[C@H](C)NC(=O)c1ccc(-c2ccc(-c3ccc(-c4ccc(C(=O)N[C@@H](CC(=O)O)C(=O)N[C@@H](CC(=O)O)C(=O)N[C@@H](CC(=O)O)C(=O)NC(CC(=O)O)C(=O)O)s4)s3)s2)s1)C(C)C)C(=O)O</smiles>

HO-DDDD-OT4-AVAV-OH (2): Solid supported Wang-DDDD-NH 2 peptide $(0.2 \mathrm{mmol})$ was $N$ acylated with $\left[2,2^{\prime}: 5^{\prime}, 2^{\prime \prime}: 5^{\prime \prime}, 2^{\prime \prime}\right.$-quaterthiophene]-5,5"'-dicarboxylic acid and then subjected to the on-resin activation procedure. A solution of $\mathrm{HO}-\mathrm{VAVA}-\mathrm{NH}_{2}(0.4 \mathrm{mmol})$ was prepared and added to the resin and mixed for 16 hours. Following general cleavage, work-up, and HPLC purification, the peptide was obtained as a light orange powder $(0.007 \mathrm{mmol}, 3 \%)$. DATA UV-Vis $(\mathrm{H} 2 \mathrm{O}) \lambda / \mathrm{nm}$ (pH 10): 420. MS (ESI) m/z 1217.4 (M-1H) (calc. 1217.3), m/z $608.5(\mathrm{M}-2 \mathrm{H}) / 2$ (calc. 608.0), m/z 405.1 (M- 3H)/3 (calc. 405.0). 
<smiles>CC(NC(=O)c1ccc(-c2ccc(-c3ccc(-c4ccc(C(=O)O)s4)s3)s2)s1)C(=O)N[C@@H](C)C(=O)N[C@@H](C(=O)N[C@@H](C)C(=O)N[C@H](C(=O)N[C@@H](CC(=O)O)C(=O)N[C@@H](CC(=O)O)C(=O)N[C@@H](CC(=O)O)C(=O)N[C@@H](CC(=O)O)C(=O)O)C(C)C)C(C)C</smiles>

HO-DDDD-VAVA-OT4-OH (3): Solid supported Wang-DDDD-NH 2 peptide (0.2 mmol) was $N$ acylated with HO-VAVA-NHFmoc $(0.4 \mathrm{mmol})$. The terminal Fmoc was deprotected and capped with $\left[2,2^{\prime}: 5^{\prime}, 2^{\prime \prime}: 5 ", 2^{\prime \prime}-\right.$-quaterthiophene]-5,5'"-dicarboxylic acid. Following general cleavage, workup, and HPLC purification, the peptide was obtained as a light orange powder $(0.016 \mathrm{mmol}, 8 \%)$. DATA UV-Vis (H2O) $\lambda / \mathrm{nm}$ (pH 10): 417. MS (ESI) m/z 1217.1 (M-1H) (calc. 1217.3), m/z 608.5 (M-2H)/2 (calc. 608.0).<smiles></smiles>

HO-DDDD-OT4-AVAV-C8 (4-C8): Solid supported Wang-DDDD-NH 2 peptide (0.2 mmol) was $N$-acylated with $\left[2,2^{\prime}: 5^{\prime}, 2^{\prime \prime}: 5^{\prime \prime}, 2^{\prime \prime}\right.$-quaterthiophene]-5,5"'-dicarboxylic acid and subjected to the onresin activation procedure. A solution of $\mathrm{HO}-\mathrm{VAVA}-\mathrm{NH}_{2}(0.4 \mathrm{mmol})$ was prepared and added to the resin and mixed for 16 hours. The terminal carboxylic acid was again subjected to the on-resin activation procedure. A solution of octylamine $(0.6 \mathrm{mmol}, 0.10 \mathrm{~mL})$ in NMP was added and stirred for 16 hours. Following general cleavage, work-up, and HPLC purification, the peptide was obtained as a light orange powder $(0.002 \mathrm{mmol}, 1 \%)$. DATA UV-Vis (H2O) $\lambda / \mathrm{nm}(\mathrm{pH} \mathrm{10):} 413$. MS (ESI) m/z 1328.3 (M-1H) (calc. 1328.4), m/z 664.3 (M-2H)/2 (calc. 663.7), m/z 442.9 (M3H)/3 (calc. 442.1). 


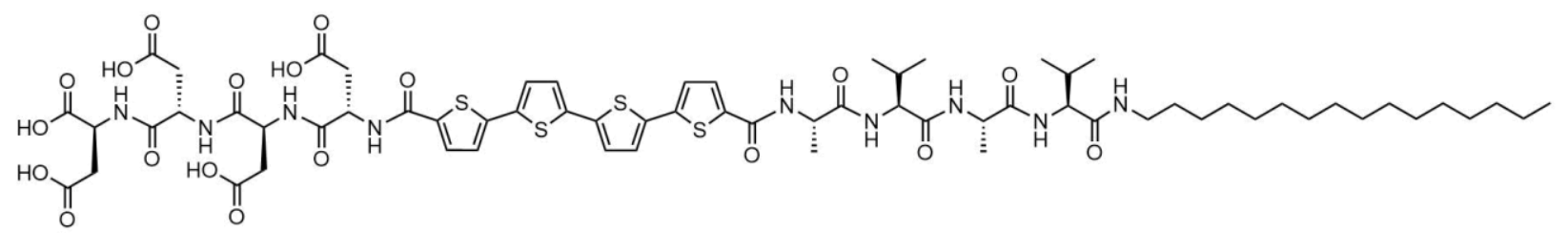

HO-DDDD-OT4-AVAV-C16 (4-16): Solid supported Wang-DDDD-NH 2 (0.2 mmol) peptide was $N$-acylated with $\left[2,2^{\prime}: 5^{\prime}, 2^{\prime \prime}: 5^{\prime \prime}, 2\right.$ "'-quaterthiophene]-5,5"'-dicarboxylic acid and subjected to the on-resin activation procedure. A solution of $\mathrm{HO}-\mathrm{VAVA}-\mathrm{NH}_{2}(0.4 \mathrm{mmol})$ was prepared and added to the resin and mixed for 16 hours. The terminal carboxylic acid was again subjected to the onresin activation procedure. A solution of hexadecylamine $(0.6 \mathrm{mmol}, 0.14 \mathrm{~mL})$ in NMP was added and stirred for 16 hours. Following general cleavage, work-up, and HPLC purification, the peptide was obtained as a light orange powder $(0.002 \mathrm{mmol}, 1 \%)$. DATA UV-Vis $(\mathrm{H} 2 \mathrm{O}) \lambda / \mathrm{nm}(\mathrm{pH} 10)$ : 420. MS (ESI) m/z $1440.5(\mathrm{M}-1 \mathrm{H})$ (calc. 1440.5), m/z $720.6(\mathrm{M}-2 \mathrm{H}) / 2$ (calc. 719.7), m/z 480.3 $(\mathrm{M}-3 \mathrm{H}) / 3$ (calc. 479.5).<smiles>CCCCCCCCNC(=O)c1ccc(-c2ccc(-c3ccc(-c4ccc(C(=O)NC(C)C(=O)NC(C(=O)N[C@@H](C)C(=O)NC(C(=O)N[C@@H](CC(=O)O)C(=O)NC(CC(=O)O)C(=O)N[C@@H](CC(=O)O)C(=O)NC(CC(=O)O)C(=O)O)C(C)C)C(C)C)s4)s3)s2)s1</smiles>
HO-DDDD-VAVA-OT4-C8 (5-C8): Solid supported Wang-DDDD-NH $2(0.2 \mathrm{mmol})$ peptide was $N$-acylated with HO-VAVA-NHFmoc $(0.4 \mathrm{mmol})$. The terminal Fmoc was deprotected and capped with $\left[2,2^{\prime}: 5^{\prime}, 2^{\prime \prime}: 5^{\prime \prime}, 2^{\prime \prime}\right.$-quaterthiophene]-5,5"'-dicarboxylic acid and subjected to the onresin activation procedure. A solution of octylamine $(0.6 \mathrm{mmol}, 0.10 \mathrm{~mL})$ in NMP was prepared and added to the resin and mixed for 16 hours. Following general cleavage, work-up, and HPLC purification, the peptide was obtained as a light orange powder $(0.004 \mathrm{mmol}, 2 \%)$. DATA UV-Vis (H2O) $\lambda / \mathrm{nm}$ (pH 10): 417. MS (ESI) m/z 1328.2 (M-1H) (calc. 1238.4), m/z 663.7 (M-2H)/2 (calc. 663.7). 


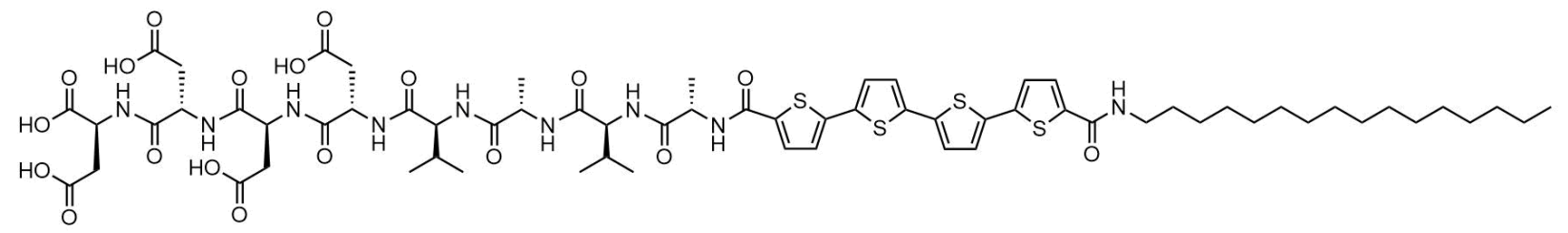

HO-DDDD-VAVA-OT4-16 (5-C16): Solid supported Wang-DDDD-NH $\mathrm{N}_{2}$ peptide $(0.2 \mathrm{mmol})$ was $N$-acylated with HO-VAVA-NHFmoc $(0.4 \mathrm{mmol})$. The terminal Fmoc was deprotected and capped with $\left[2,2^{\prime}: 5^{\prime}, 2^{\prime \prime}: 5^{\prime \prime}, 2^{2}\right.$-'quaterthiophene $]-5,5^{\prime \prime}$-dicarboxylic acid and subjected to the onresin activation procedure. A solution of hexadecylamine $(0.6 \mathrm{mmol}, 0.14 \mathrm{~mL})$ in NMP was prepared and added to the resin and mixed for 16 hours. Following general cleavage, work-up, and HPLC purification, the peptide was obtained as a light orange powder $(0.001 \mathrm{mmol}, 1 \%)$. UV-Vis (H2O) $\lambda / \mathrm{nm}$ (pH 10): 402. MS (ESI) m/z 1440.31 (M-1H) (calc. 1440.5), m/z 720.45 (M-2H)/2 (calc. 719.7). 


\section{ESI Mass Spectra:}

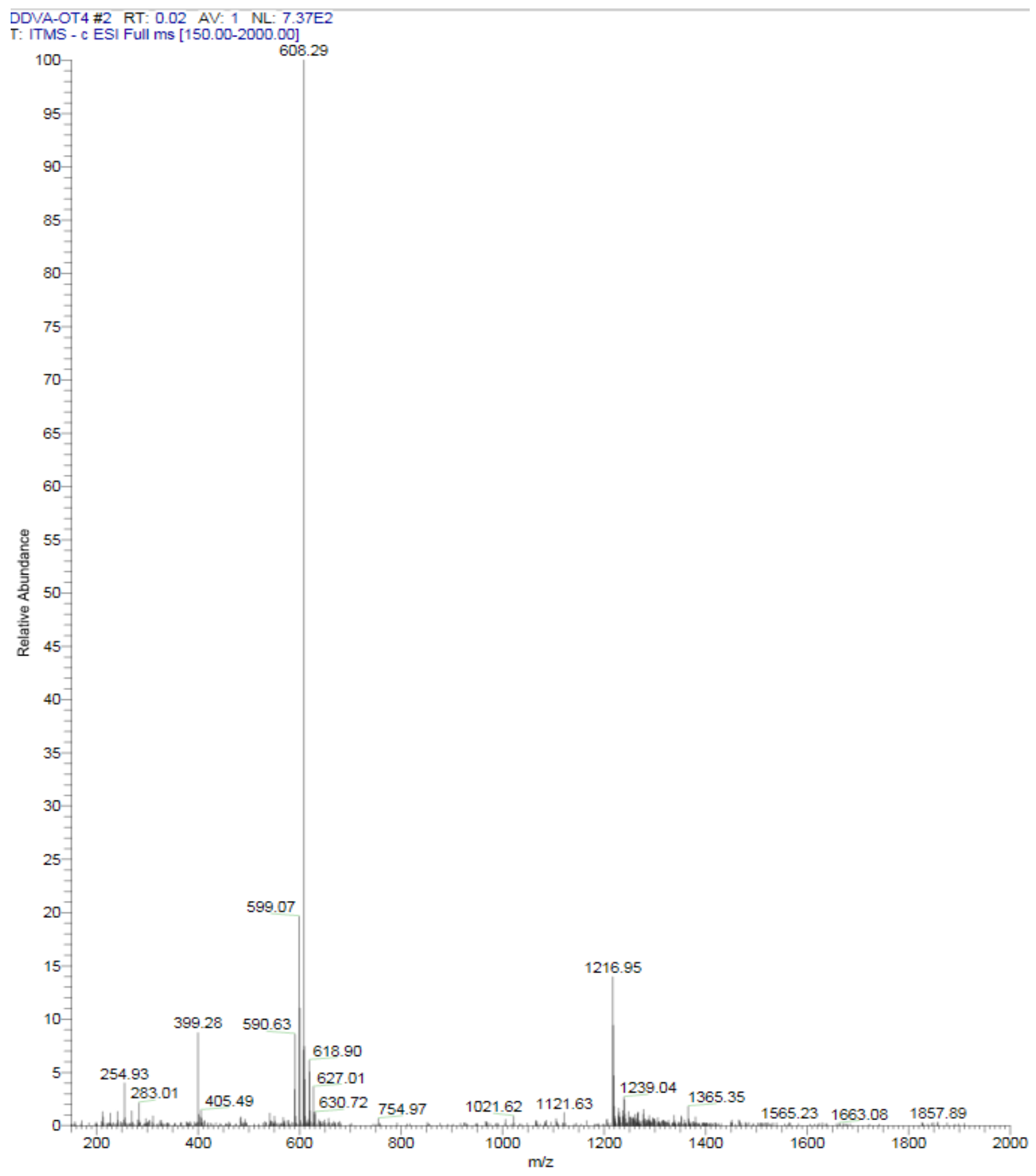

Figure S7. ESI spectrum of HO-DDVA-OT4-AVDD-OH peptide (1). MS (ESI) m/z 1217.0 (M1H) (calc. 1217.3), m/z 608.3 (M-2H)/2 (calc. 608.7). 


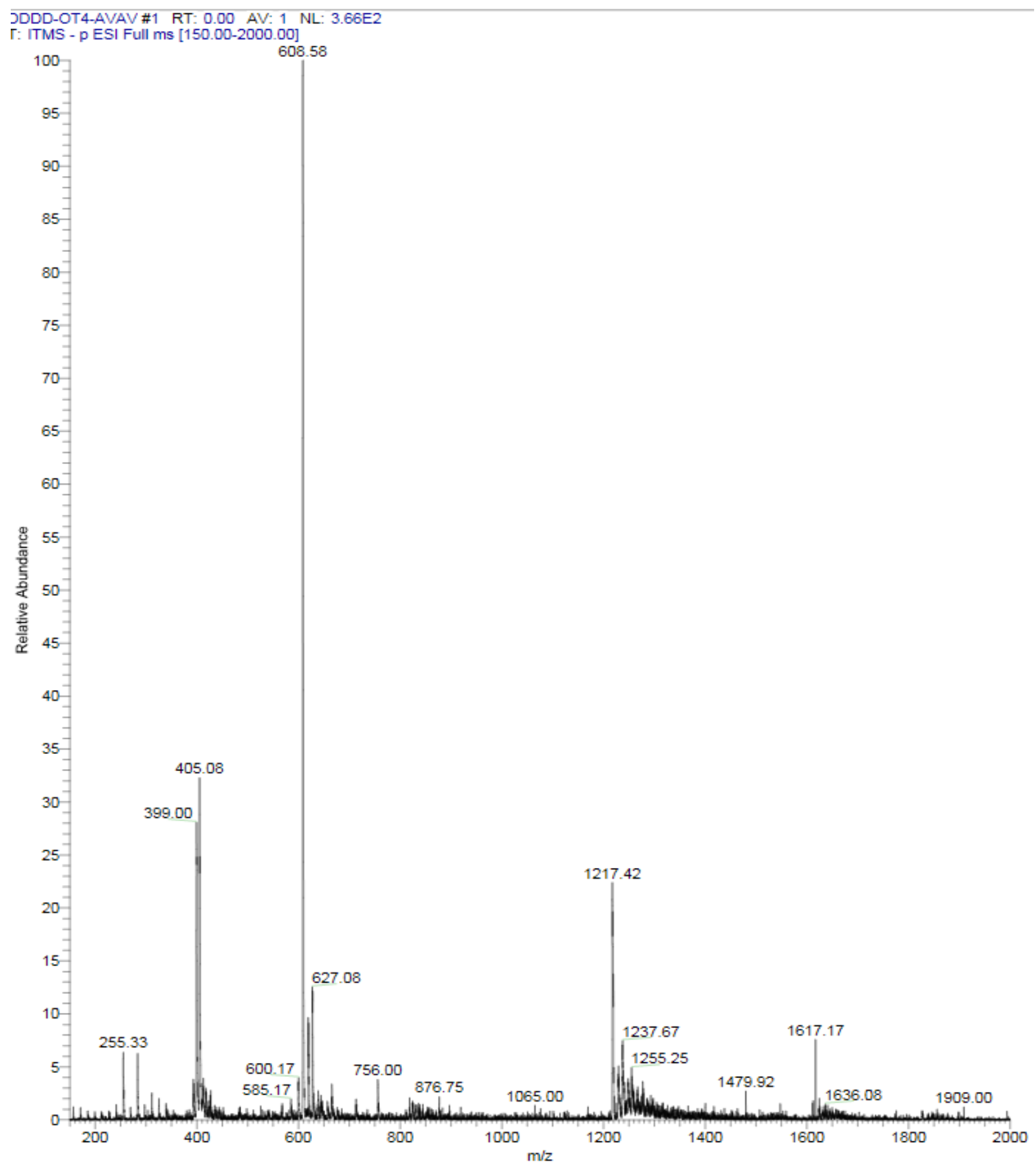

Figure S8. ESI spectrum of HO-DDDD-OT4-AVAV-OH peptide (2). MS (ESI) m/z 1217.4 (M1H) (calc. 1217.3), m/z 608.5 (M-2H)/2 (calc. 608.0), m/z 405.1 (M- 3H)/3 (calc. 405.0). 


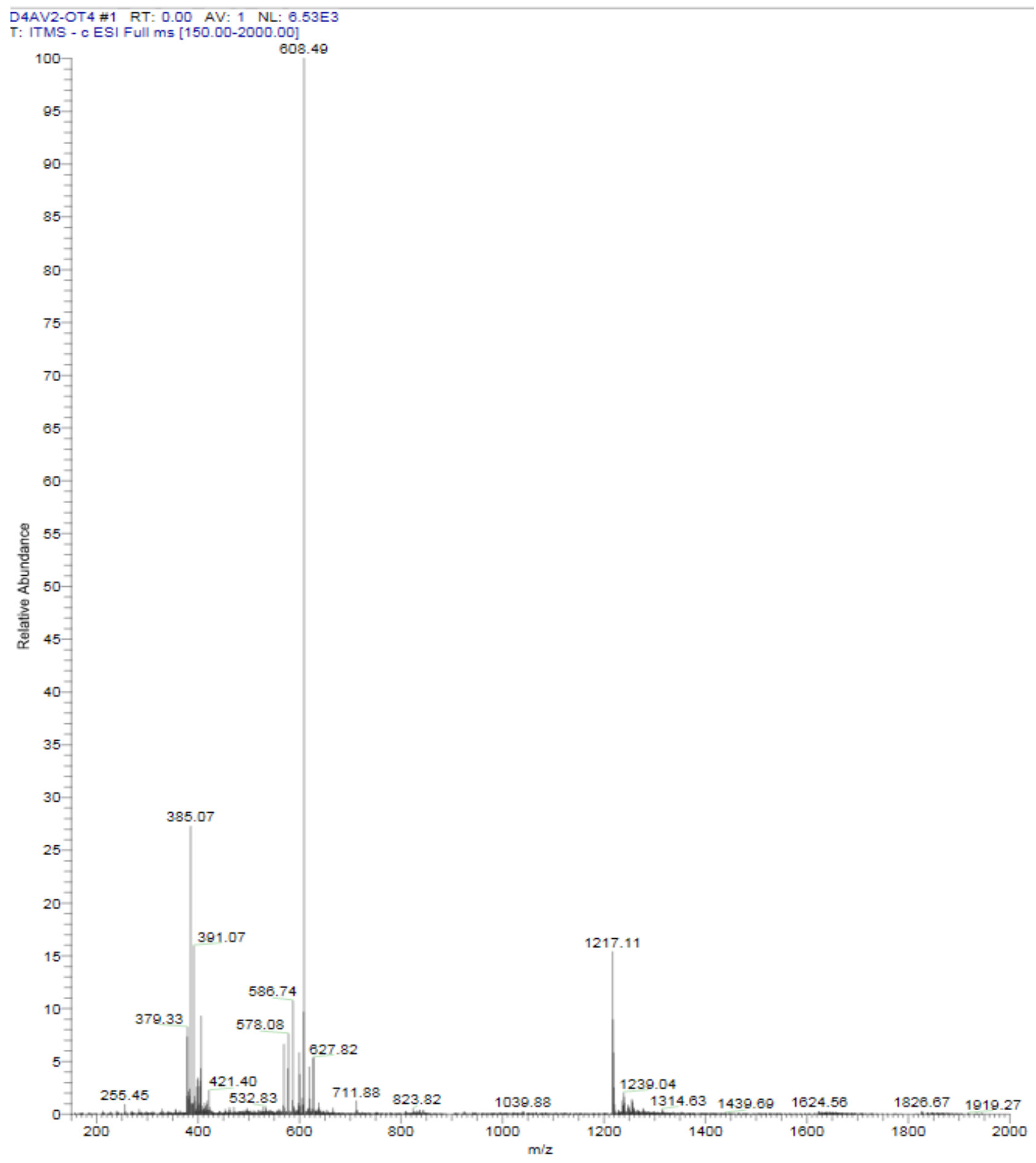

Figure S9. ESI spectrum of HO-DDDD-VAVA-OT4-OH peptide (3). MS (ESI) m/z 1217.1 (M1H) (calc. 1217.3), m/z 608.5 (M-2H)/2 (calc. 608.0). 


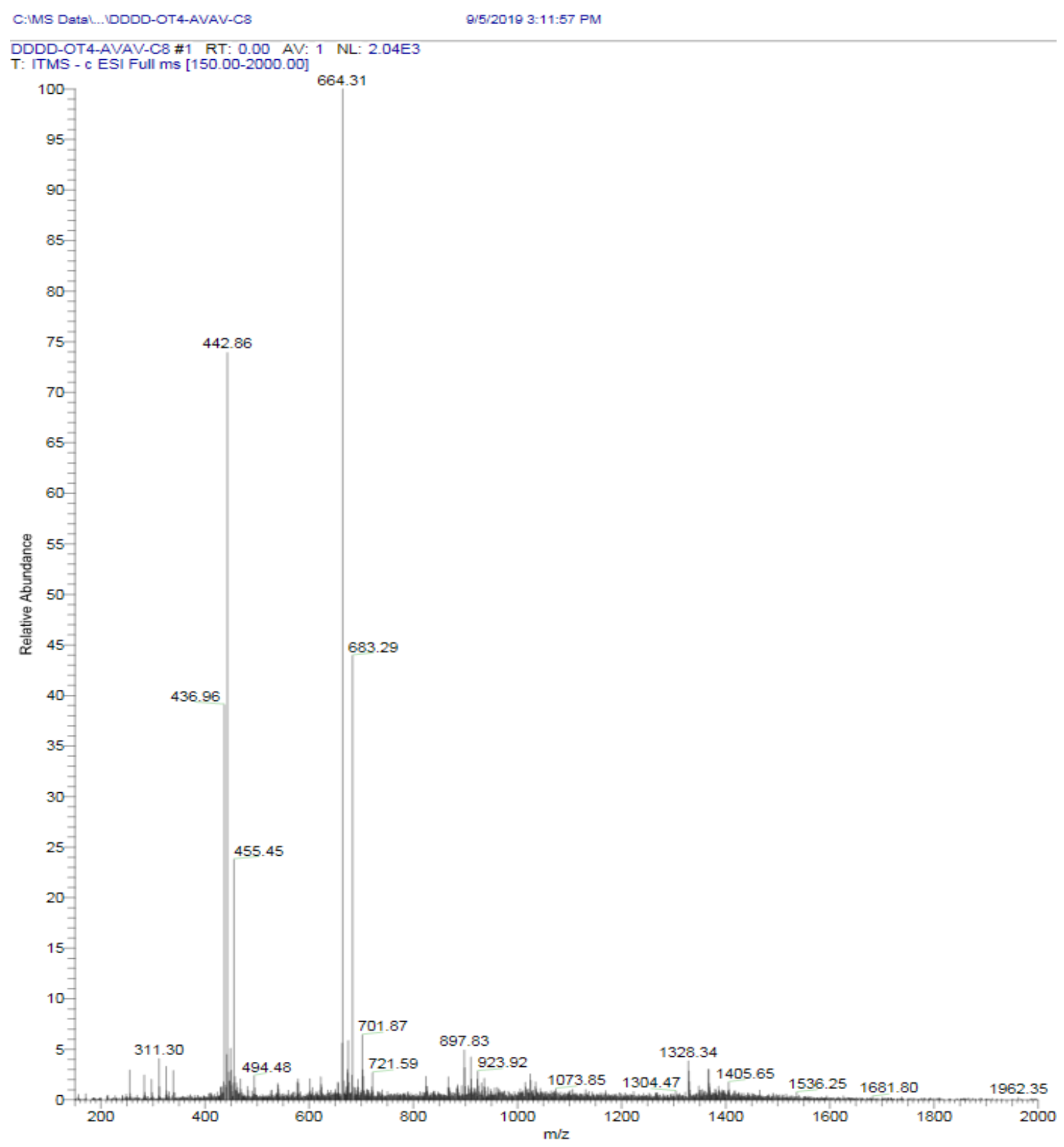

Figure S10. ESI spectrum of HO-DDDD-OT4-AVAV-C8 peptide (4-C8). MS (ESI) m/z 1328.3 (M-1H) (calc. 1328.4), m/z 664.3 (M-2H)/2 (calc. 663.7), m/z 442.9 (M-3H)/3 (calc. 442.1). 


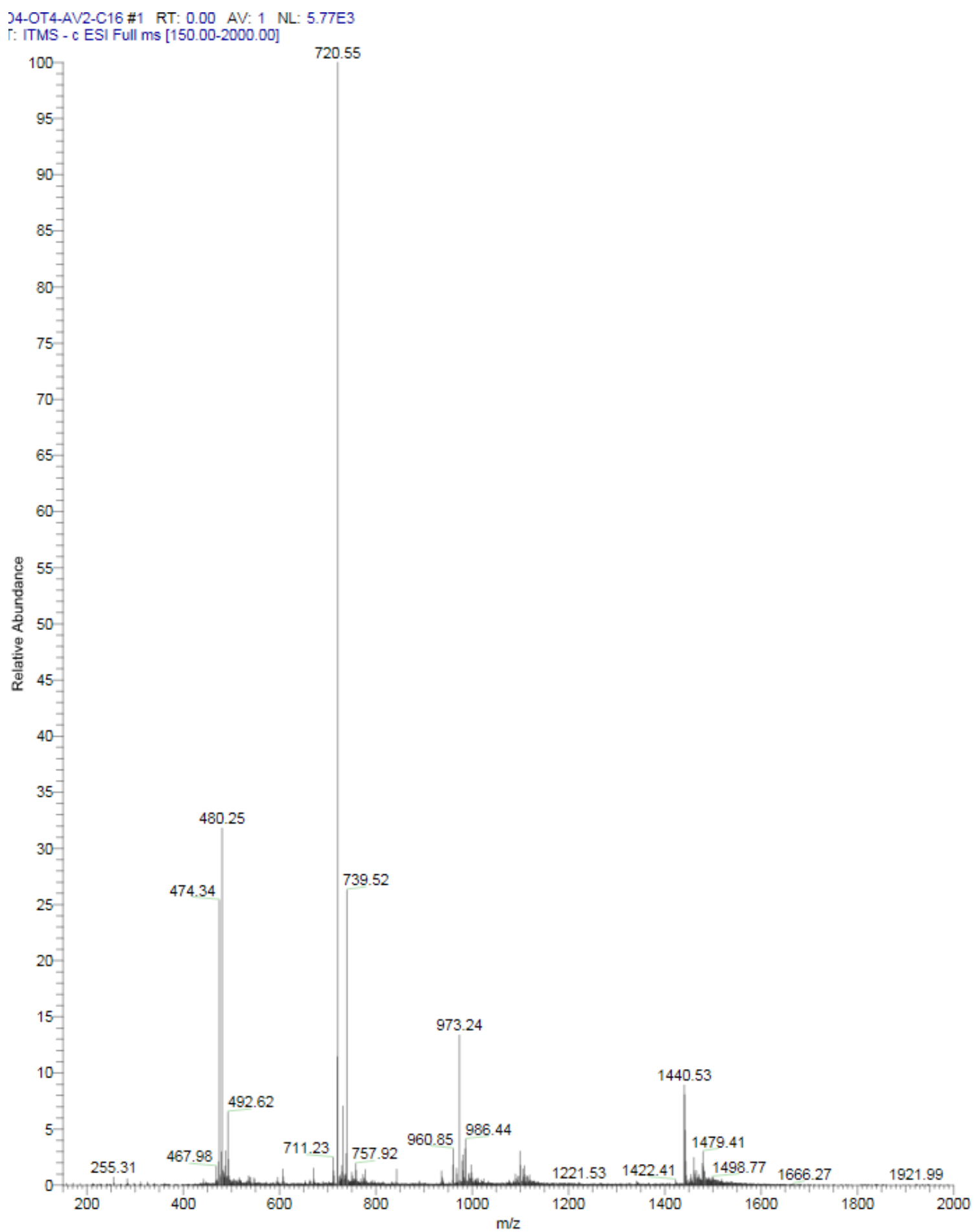

Figure S11. ESI spectrum of HO-DDDD-OT4-AVAV-C16 peptide (4-C16). MS (ESI) m/z $1440.5(\mathrm{M}-1 \mathrm{H})$ (calc. 1440.5), m/z $720.6(\mathrm{M}-2 \mathrm{H}) / 2$ (calc. 719.7), m/z $480.3(\mathrm{M}-3 \mathrm{H}) / 3$ (calc. 479.5). 


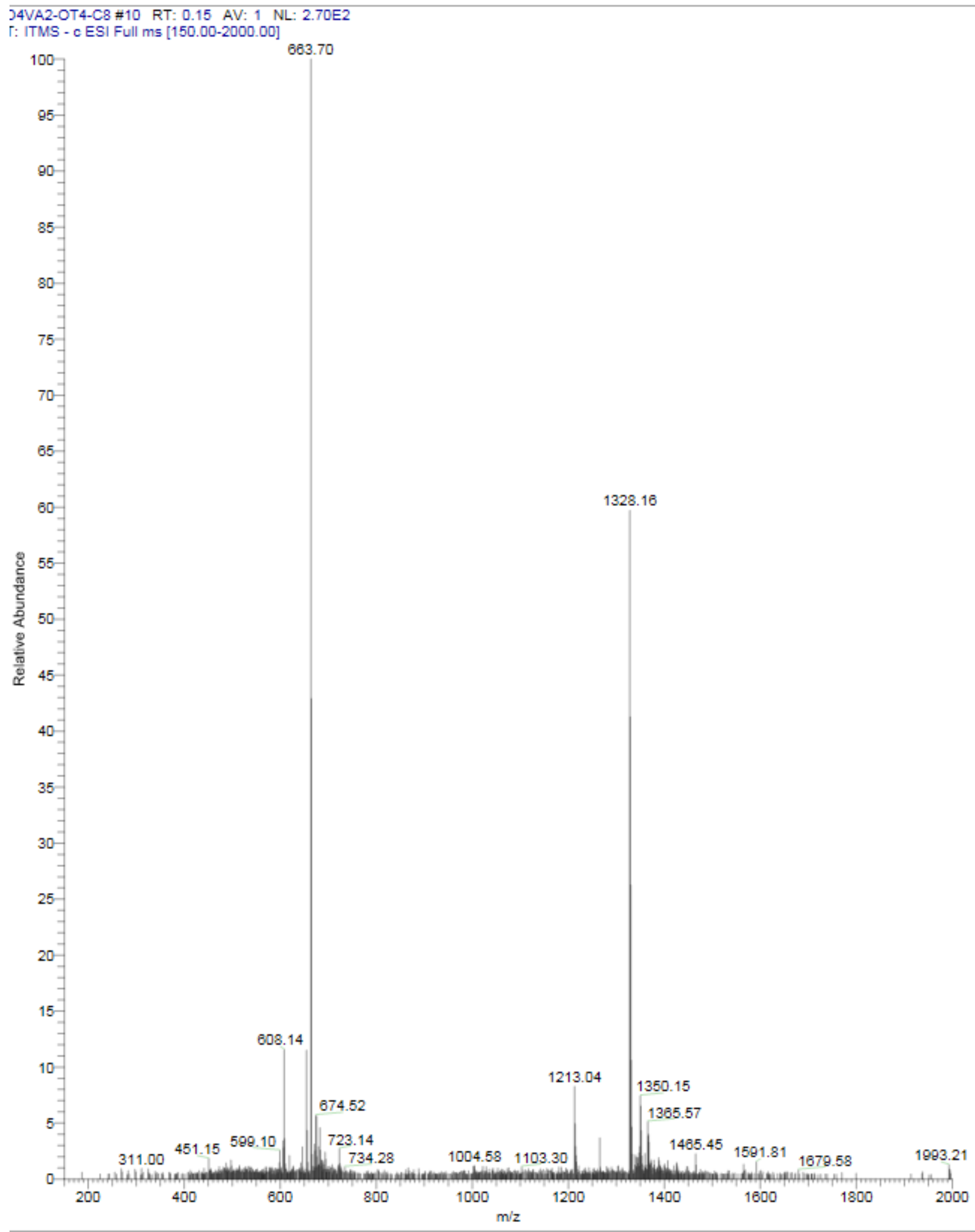

Figure S12. ESI spectrum of HO-DDDD-VAVA-OT4-C8 peptide (5-C8). MS (ESI) m/z 1328.2 (M-1H) (calc. 1238.4), m/z 663.7 (M-2H)/2 (calc. 663.7). 


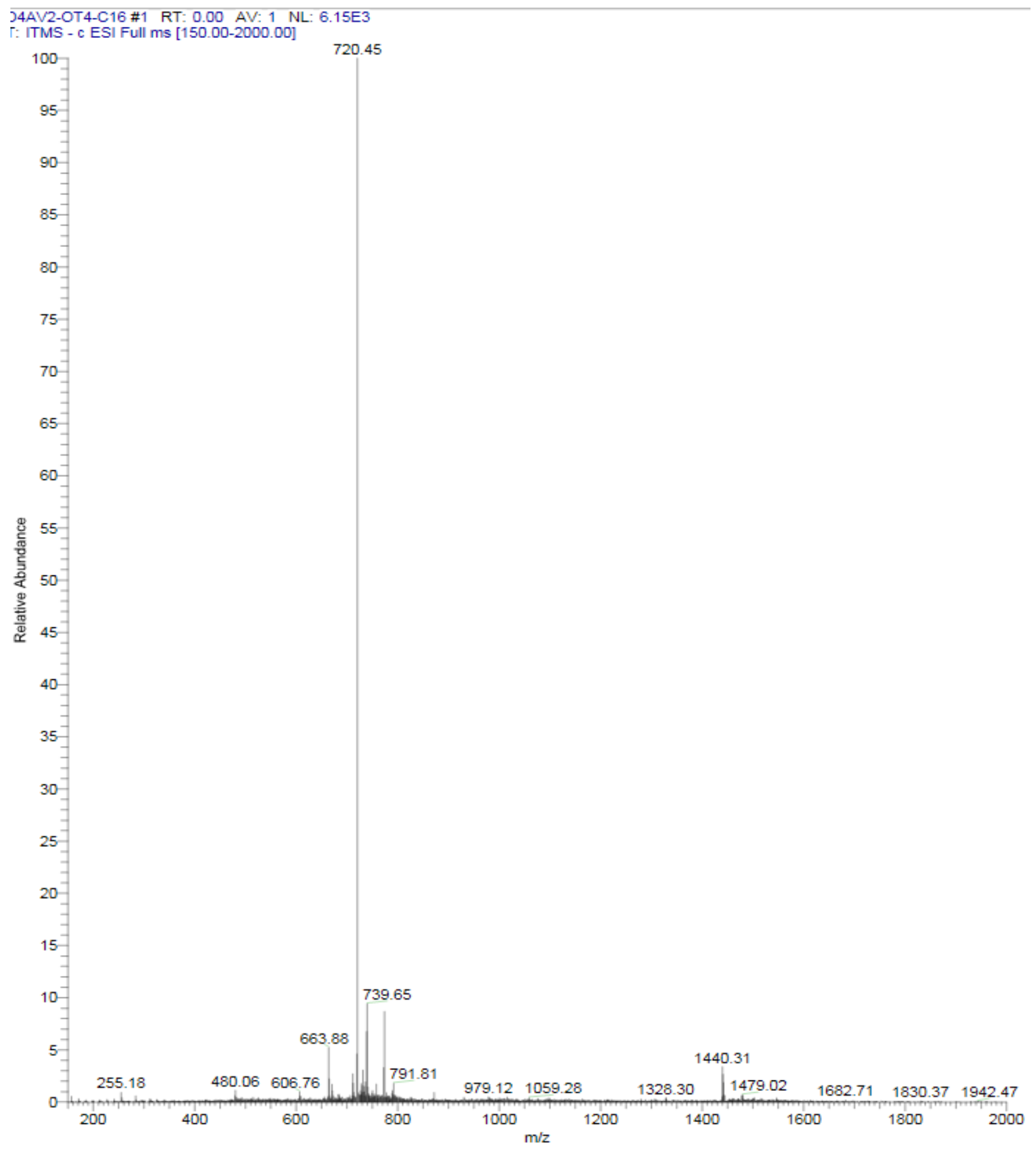

Figure S13. ESI spectrum of HO-DDDD-VAVA-OT4-C16 peptide (5-C16). MS (ESI) m/z $1440.31(\mathrm{M}-1 \mathrm{H})$ (calc. 1440.5), m/z 720.45 (M-2H)/2 (calc. 719.7). 


\section{HPLC Traces of Purified Peptides}

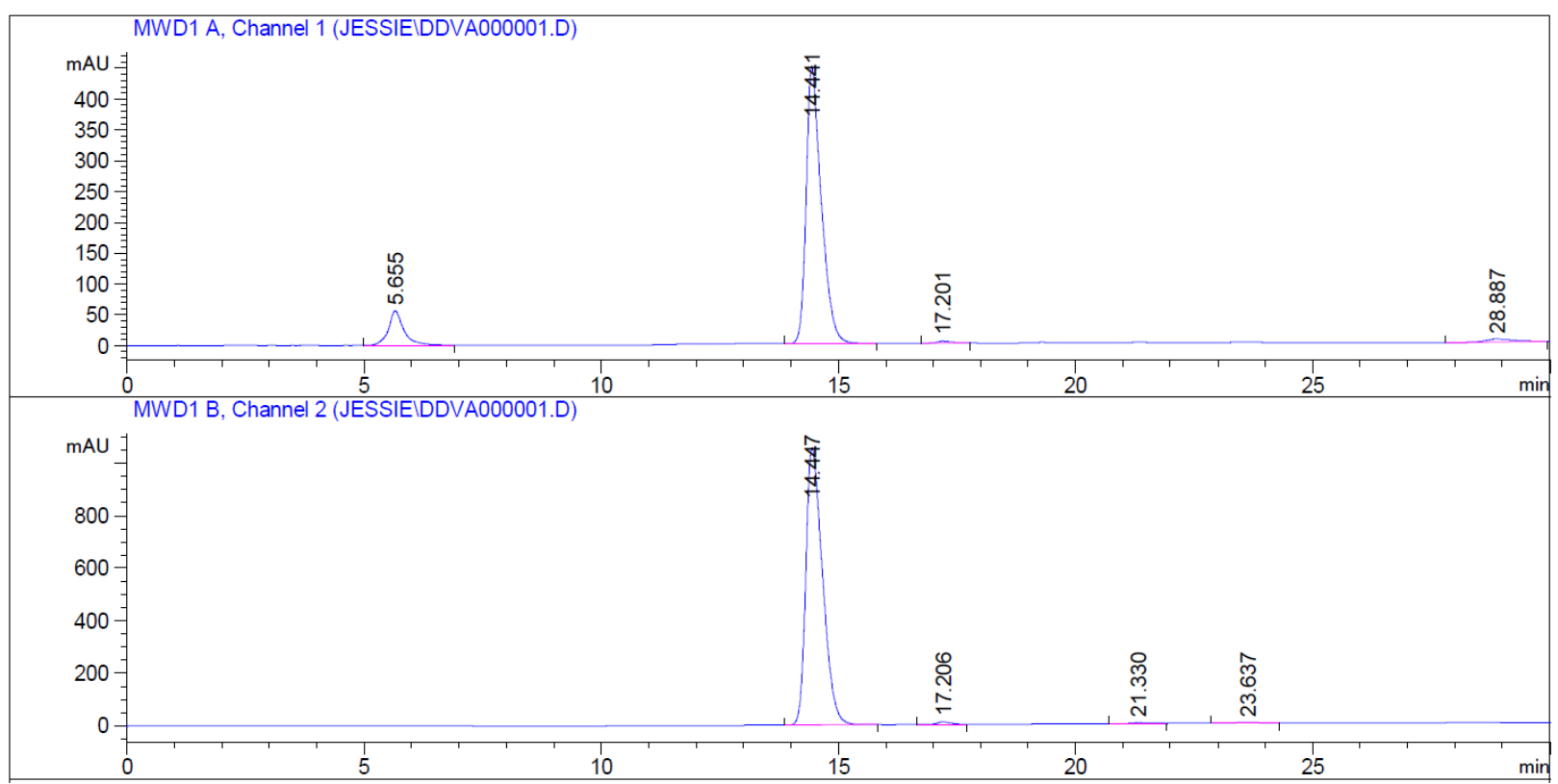

Figure S14: Analytical HPLC trace of purified HO-DDVA-OT4-AVDD-OH peptide (1). Traces monitoring $260 \mathrm{~nm}$ (top) and $420 \mathrm{~nm}$ (bottom). Method: Linear gradient of 10\%-50\% acetonitrile/buffer over 25 minutes, then linear gradient of 50\%-10\% over 5 minutes.

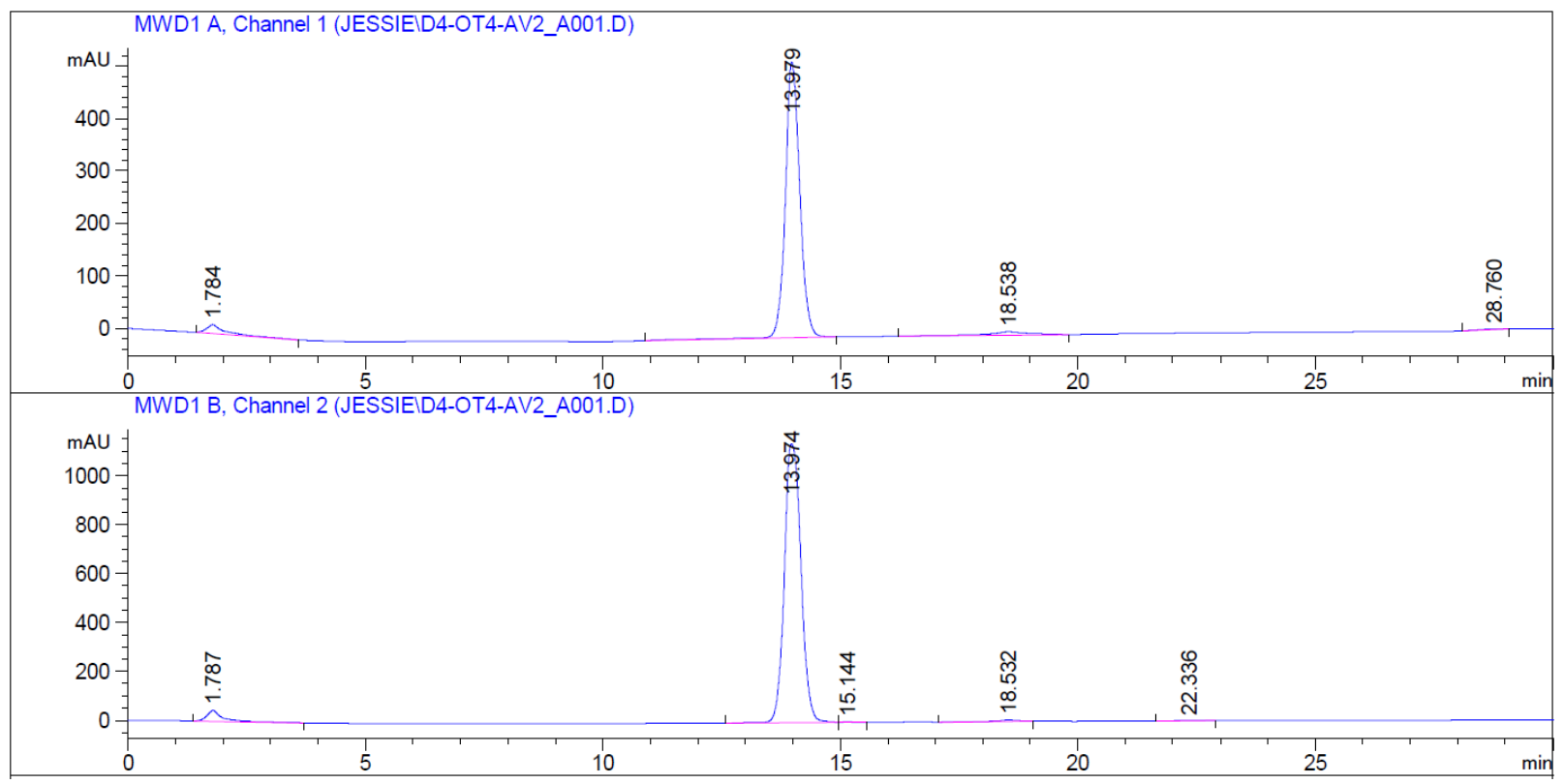

Figure S15. Analytical HPLC trace of purified HO-DDDD-OT4-AVAV-OH peptide (2). Traces monitoring $260 \mathrm{~nm}$ (top) and $420 \mathrm{~nm}$ (bottom). Method: Linear gradient of 10\%-50\% acetonitrile/buffer over 25 minutes, then linear gradient of 50\%-10\% over 5 minutes. 


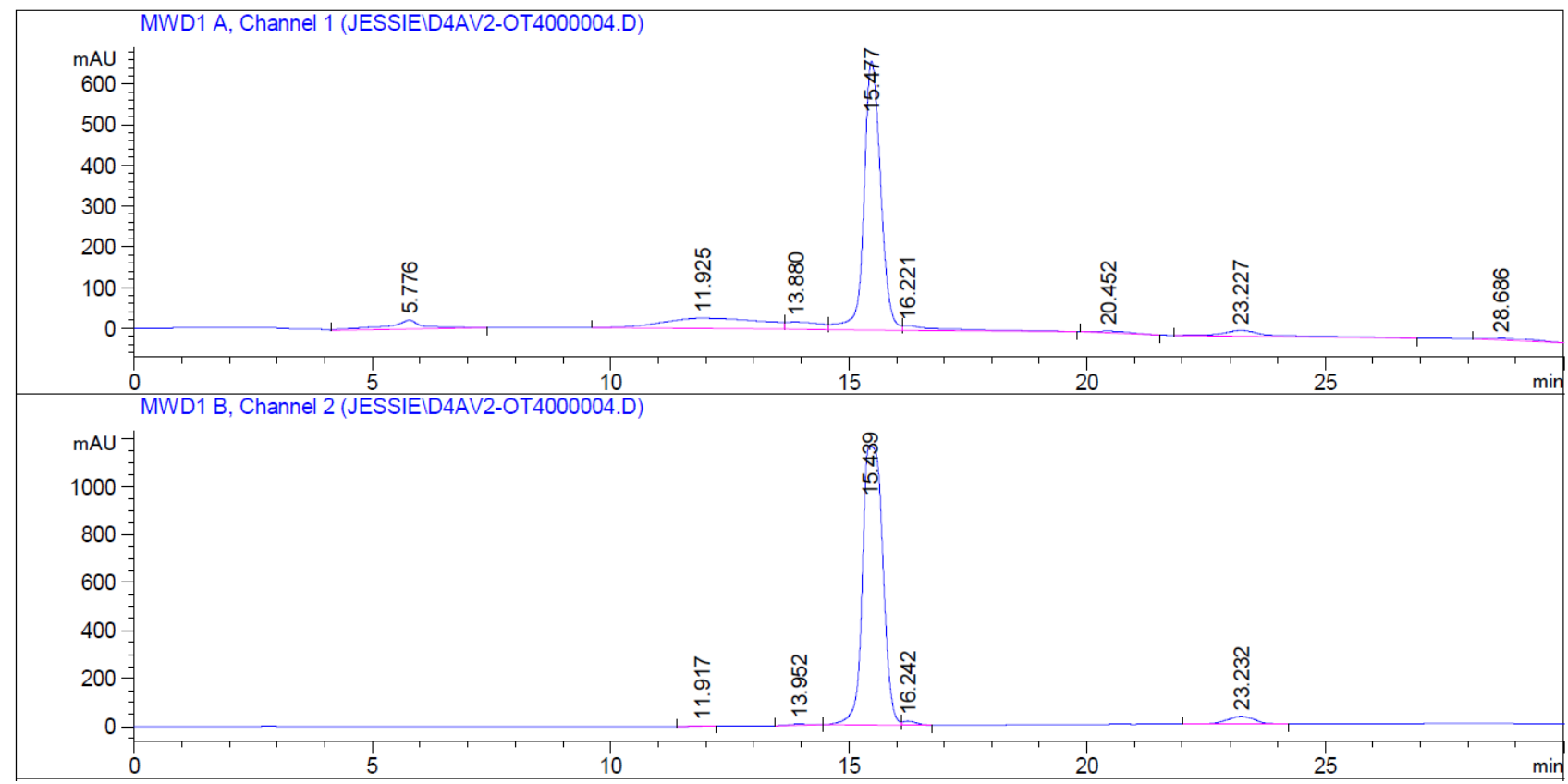

Figure S16. Analytical HPLC trace of purified HO-DDDD-VAVA-OT4-OH peptide (3). Traces monitoring $260 \mathrm{~nm}$ (top) and $420 \mathrm{~nm}$ (bottom). Method: Linear gradient of 10\%-50\% acetonitrile/buffer over 25 minutes, then linear gradient of $50 \%-10 \%$ over 5 minutes.

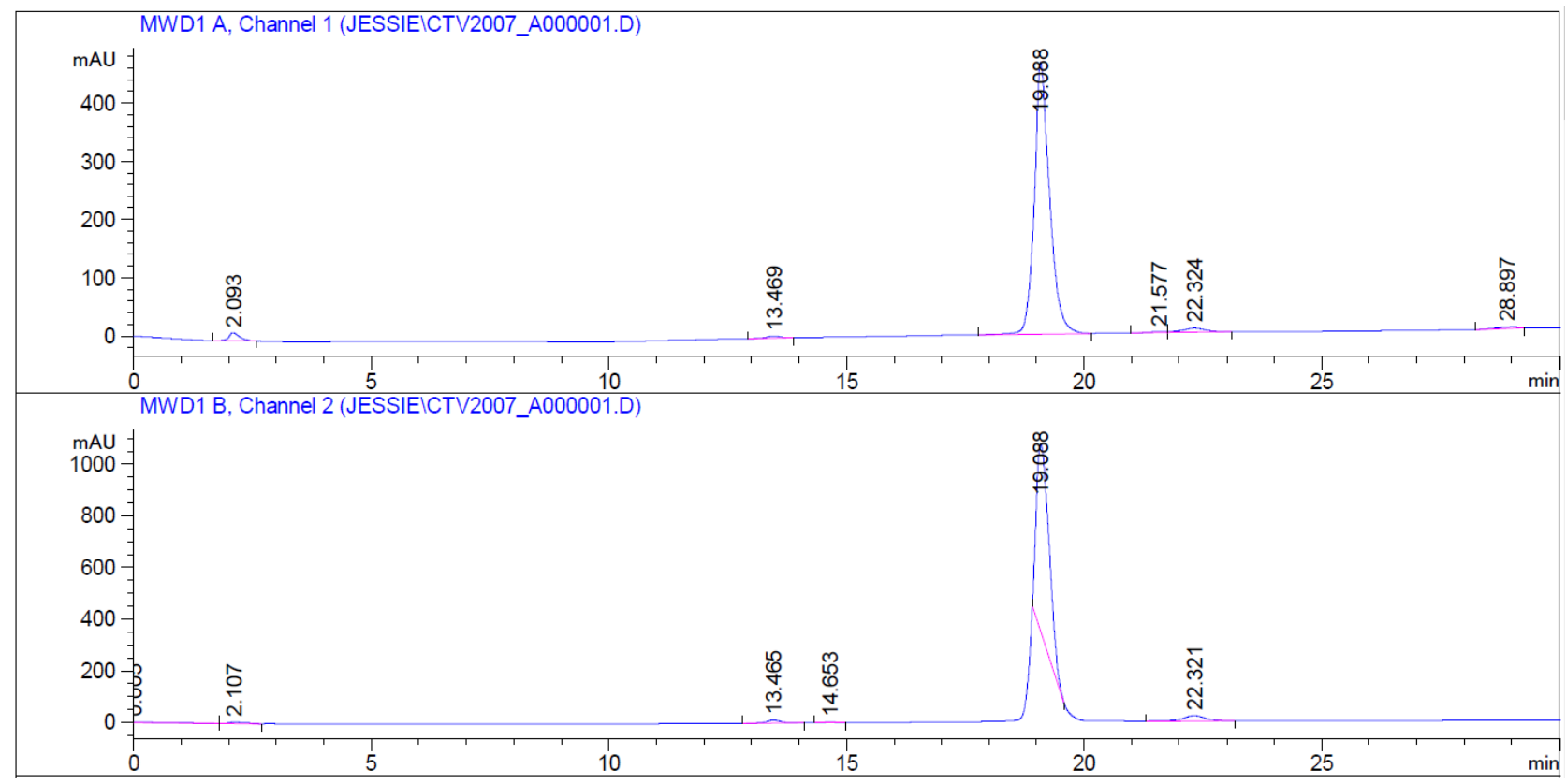

Figure S17. Analytical HPLC trace of purified HO-DDDD-OT4-AVAV-C8 peptide (4-C8). Traces monitoring $260 \mathrm{~nm}$ (top) and $420 \mathrm{~nm}$ (bottom). Method: Linear gradient of 20\%-60\% acetonitrile/buffer over 25 minutes, then linear gradient of $60 \%-20 \%$ over 5 minutes. 


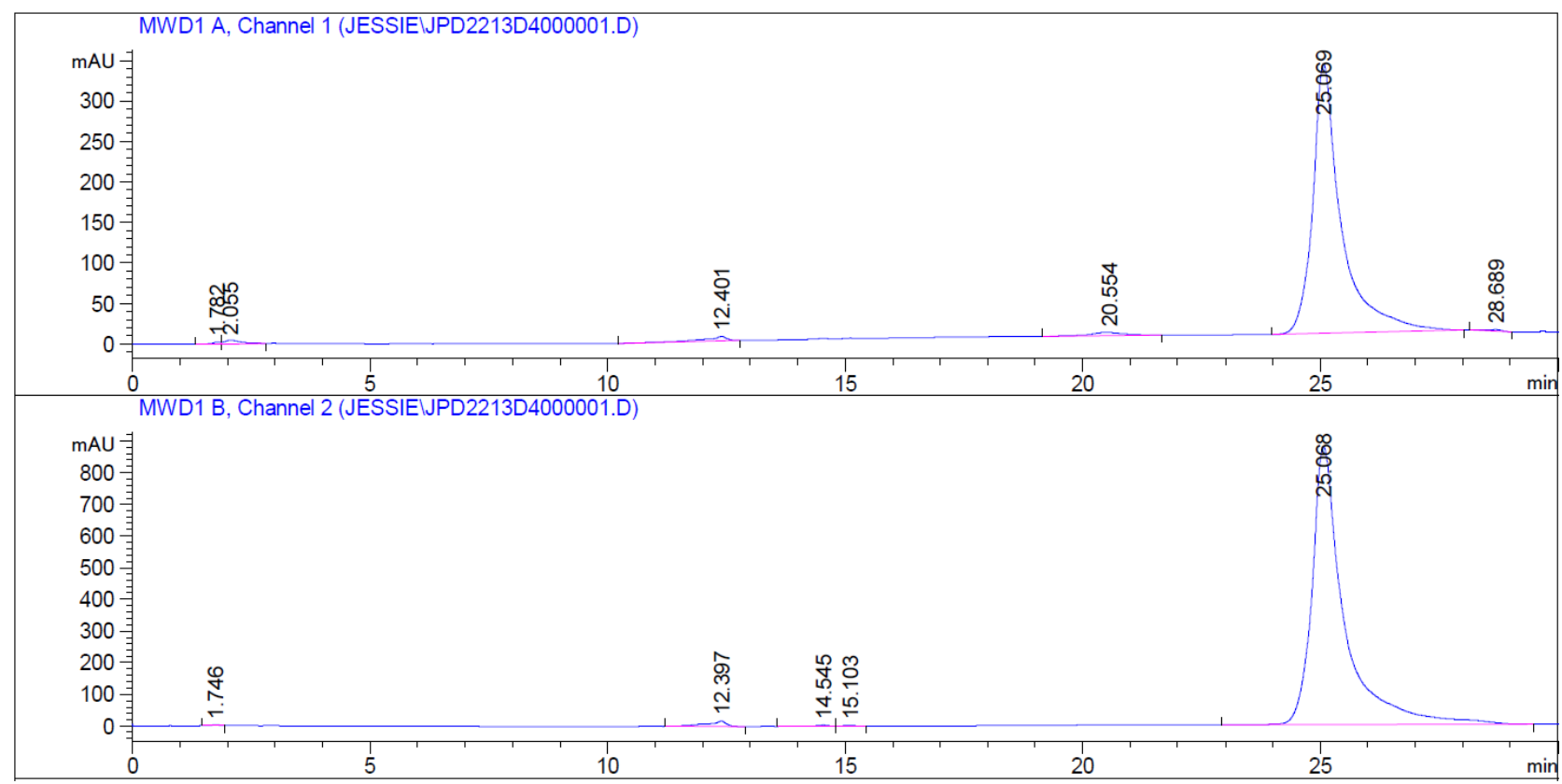

Figure S18. Analytical HPLC trace of purified HO-DDDD-OT4-AVAV-C16 peptide (4-C16). Traces monitoring $260 \mathrm{~nm}$ (top) and $420 \mathrm{~nm}$ (bottom). Method: Linear gradient of 30\%-70\% acetonitrile/buffer over 25 minutes, then linear gradient of $70 \%-30 \%$ over 5 minutes.

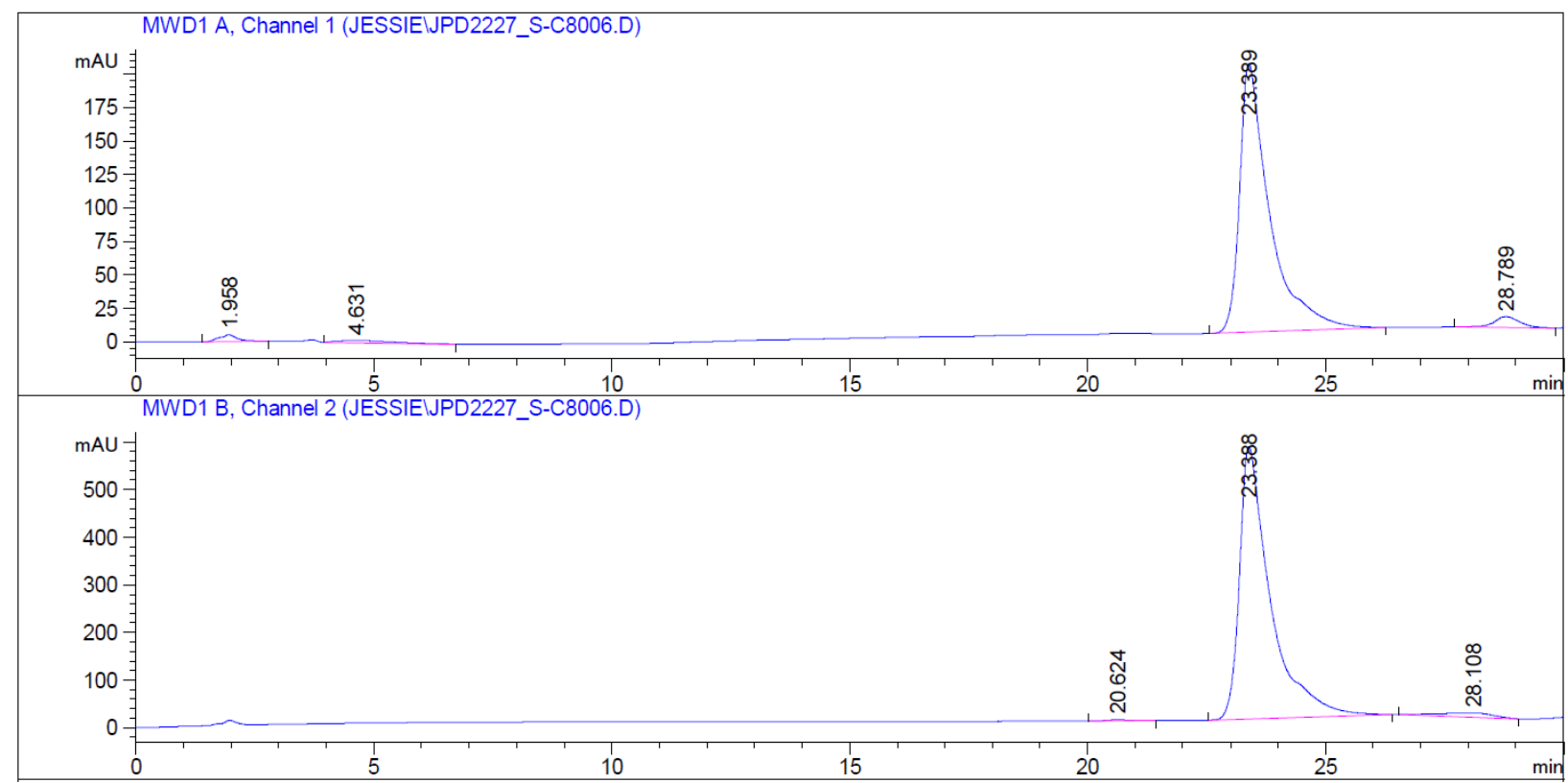

Figure S19. Analytical HPLC trace of purified HO-DDDD-VAVA-OT4-C8 peptide (5-C8). Traces monitoring $260 \mathrm{~nm}$ (top) and $420 \mathrm{~nm}$ (bottom). Method: Linear gradient of 20\%-60\% acetonitrile/buffer over 25 minutes, then linear gradient of $60 \%-20 \%$ over 5 minutes. 


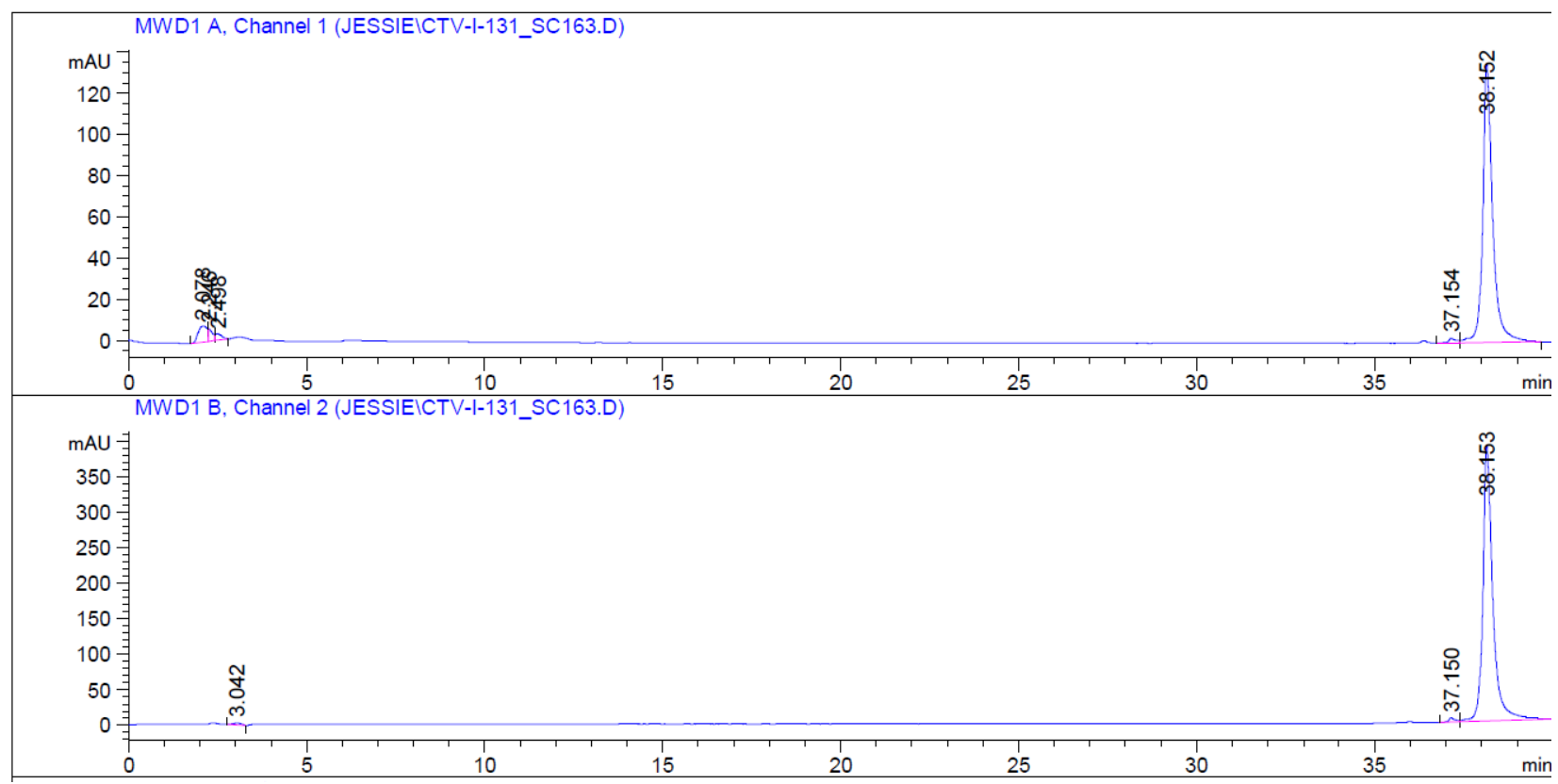

Figure S20. Analytical HPLC trace of purified HO-DDDD-VAVA-OT4-C16 peptide (5-C16). Traces monitoring $260 \mathrm{~nm}$ (top) and $420 \mathrm{~nm}$ (bottom). Method: Linear gradient of 30\%-70\% acetonitrile/buffer over 25 minutes, then linear gradient of $70 \%-30 \%$ over 5 minutes

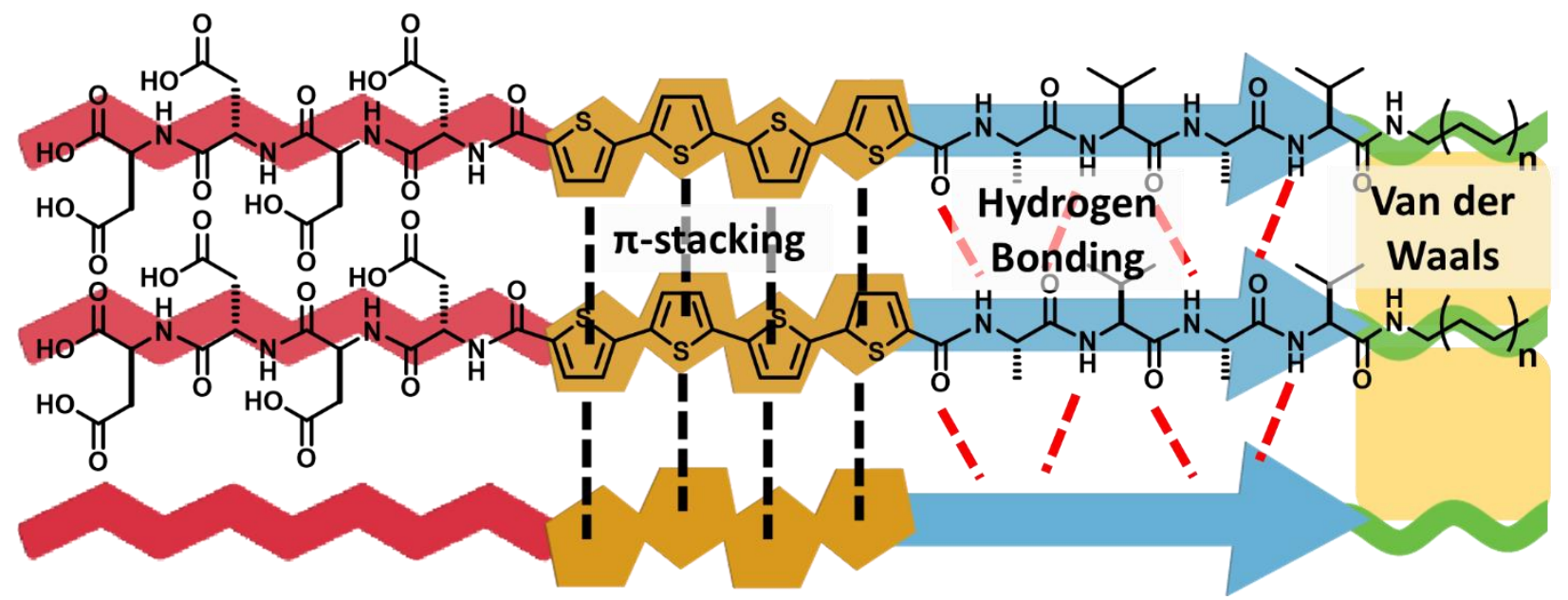

Figure S21: Distinct regimes of chemical character guide the assembly process and morphological outcomes in the current peptide library. 

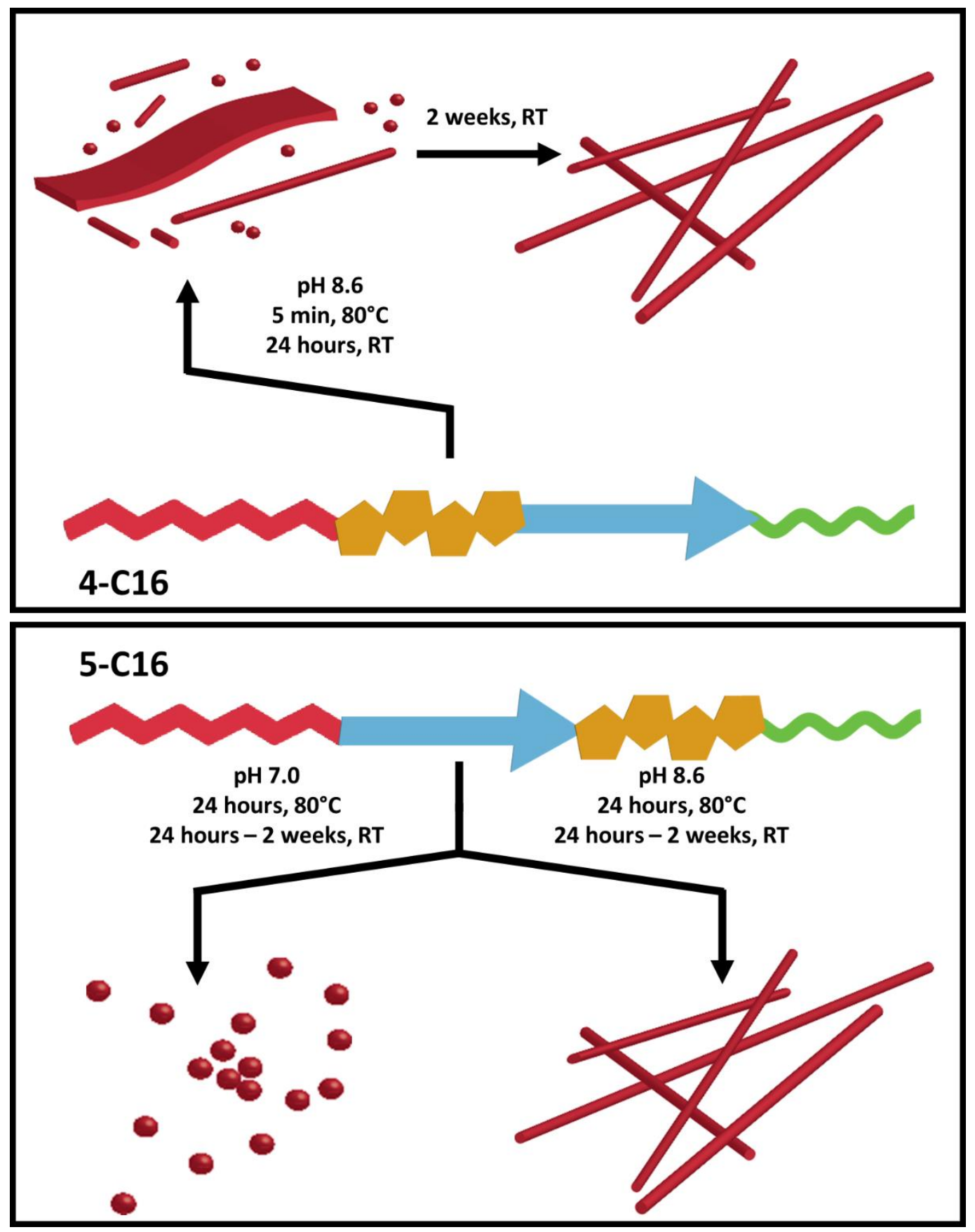

Figure S22: Assembly conditions and morphological outcomes for the 4-C16 and 5-C16 peptides.

\section{References:}

(1) Jiang, H.; Zhang, L.; Cai, J.; Ren, J.; Cui, Z.; Chen, W. Quinoidal Bithiophene as Disperse 
Dye: Substituent Effect on Dyeing Performance. Dye. Pigment. 2018, 151 (January), 363371.

(2) Capozzi, B.; Dell, E. J.; Berkelbach, T. C.; Reichman, D. R.; Venkataraman, L.; Campos, L. M. Length-Dependent Conductance of Oligothiophenes. J. Am. Chem. Soc. 2014, 136 (29), 10486-10492.

(3) Vadehra, G. S.; Wall, B. D.; Diegelmann, S. R.; Tovar, J. D. On-Resin Dimerization Incorporates a Diverse Array of p-Conjugated Functionality within Aqueous SelfAssembling Peptide Backbonesw. Chem. Commun. 2010, 46, 3947-3949.

(4) Dimerizations, C. S.; Sanders, A. M.; Dawidczyk, T. J.; Katz, H. E.; Tovar, J. D. PeptideBased Supramolecular Semiconductor Nanomaterials via Pd- Catalyzed Solid-Phase “ Dimerizations .” ACS Macro Lett. 2012, 1, 1326-1329. 